\title{
Sign, strength and shape of stream fish-based metric responses to geo- climatic and human pressure gradients
}

\author{
Vanesa Martínez-Fernández*, Joaquín Solana-Gutiérrez, Diego García De Jalón, Carlos Alonso \\ E.T.S Ingeniería de Montes, Forestal y del Medio Natural, Universidad Politécnica de Madrid, Ciudad Universitaria s/n, 28040 Madrid, Spain
}

\section{A R T I C L E I N F O}

\section{Keywords:}

Environmental assessment

Freshwater ecosystem

Fish

Geo-climatic descriptors

Agricultural land

Urban land

\begin{abstract}
A B S T R A C T
Efficient community indices and indicators are crucial for the adequate management and design of measures ensuring the ecosystem integrity. In this study we analyse the shape, sign and strength of the response of some biotic integrity indices and indicators of structure and function of fish communities along geo-climatic and human pressures gradients at catchment scale. To that purpose, $>300$ sites all over the Iberian Peninsula were characterized at the catchment scale by means of two anthropogenic drivers (agricultural and urban land proportion) and seven natural environmental descriptors covering geographical and climatic aspects. Regarding to fish-based metrics, a set of the most frequently used in stream health assessment studies have been selected, including taxonomic classic indicators, size related indicators and also recent multimetric indices created in the European context (WFD). We applied boosted regression trees that allow estimating the sign and strength of the response as well as considering non-linearity and impact thresholds. Our results show that the jointly contribution of anthropic drivers was lower than geo-climatic drivers. For most of indices and indicators, one single land cover contributed more markedly to the total deviance explained than the other, and they responded rather consistently to land-use variables, i.e., most of them responded negatively to the increase of anthropic use in the catchment. Size diversity, Fish Region Index (FRI) and maximum weight were those more sensible to agriculture land, while EFI+, mean weight, distinctness and FRI were those more sensitive to urban land. Regarding the shape of the response, urban land proportion affects normally at extremely low values, while agriculture land proportion induces smoother changes on a wider range. Our results may have practical implications, such as the selection of an efficient array of fish-based metrics to be included in ecological assessment and monitoring programs.
\end{abstract}

\section{Introduction}

An effective environmental assessment of aquatic ecosystems is crucial for the adequate management and design of measures that ensure the ecosystem integrity (Carballo et al., 2009). Current national and international environmental regulations such as the U.S. Clean Water Act and the E.U. Water Framework Directive (WFD) (2000/60/ EC 23 October 2000), have boosted the development of indices of biotic integrity (IBI sensu Karr, 1981) [henceforth indices] and bioindicators, i.e., variables informing about something different from what they actually measure (Daan, 2005) [henceforth indicators], based on biological communities (bioassessment) (Hering et al., 2006).

Efficient community indices and indicators should ideally offer reliable information from an integrated assessment of relevant structural and functional key variables of the ecosystem (Bonada et al., 2006). Then, these metrics should not only mirror large-scale diversity patterns originally shaped by natural geo-climatic drivers (Mittelbach et al., 2007; Field et al., 2009; Oberdorff et al., 2011) as it has been evidenced by previous authors (Mittelbach et al., 2007; Field et al., 2009; Oberdorff et al., 2011; Marzin et al., 2013; Feld et al., 2016), but specially they should be sensitive to common anthropogenic disturbances. For example, land use conversion to more anthropic uses (agriculture or urban settlements) has been found to affect ecosystem functions and diversity in different directions and strengths (Allan, 2004; Feld et al., 2013).

Within the wide variety of indices and indicators referring to different biological communities (Hering et al., 2006; Vidal-Abarca et al., 2016), specially fish are a suitable group to assess ecological status in rivers (Schiemer, 2000; Birk et al., 2012; Blevins et al., 2013; Izzo et al., 2016) since they have found to be sensitive to anthropogenic disturbances (Pont et al., 2007; Casatti et al., 2009; Aparicio et al., 2011). However, a detailed understanding of the responses of fish communities

\footnotetext{
* Corresponding author.

E-mail address: vanesa.mfernandez@gmail.com (V. Martínez-Fernández).
} 
to human disturbance at the catchment scale is still lacking, with frequent evidences of opposing responses.

In fact, Allan (2004) highlighted the covariation of natural and anthropogenic gradients use as one of the causes that complicate our understanding of the relationships between land cover and the ecological integrity of streams. Another reason for the lack of success in identifying pathways of influence with observed effects of anthropic land use on stream biota is the presence of nonlinear responses (Allan, 2004). Nonlinear, and even non-monotonic, responses may be caused by interactions among factors and the existence of impact thresholds. The detail of such effects has been improved by the application of machine learning techniques to the adjustment of models that reflect nonlinear responses (Clapcott et al., 2012). The shape of the response could be characterized by the identification of impact initiation and cessation thresholds, and the presence of abrupt changes in variables behaviour (Wagenhoff et al., 2017). Then, knowing the thresholds of the non-linear response could profitably increase our detailed knowledge about the response of the indices and indicators to the artificial land cover intensity and that should help to identify appropriate management actions.

In summary, there is still an active debate about whether indices and indicators really offer a reliable and generalizable indication of overall ecosystem status and the consequences of appraisal results (Hering et al., 2010; Feld et al., 2016) and studies analysing simultaneously the response of different indices and indicators to geo-climatic and anthropogenic gradients are scarce.

In this study we analyse the shape, sign and strength of the response of some biotic integrity indices and indicators of structure and function of fish communities along geo-climatic and anthropic gradients at catchment scale. A set of the most frequently used metrics in stream health assessment studies have been selected, including taxonomic classic indicators, size related indicators and also recent multimetric indices created in the European context (WFD). We applied a statistical analysis method that allows estimating the sign and strength of the response as well as considering potential non-linearities and impact thresholds. In accordance with previous studies of community indicators of freshwater fish (Dahm et al., 2013; Kail and Wolter, 2013; Benejam et al., 2016; Feld et al., 2016) our hypothesis is that the higher the degraded land proportion in the catchments, i.e., larger relative proportions of different anthropogenic covers, the poorer the ecological status according to biotic community metrics, being this relationship not necessarily linear neither monotonic. To test this hypothesis, 10 community metrics have been calculated in $>300$ sites in rivers from Iberian Peninsula.

\section{Methods}

\subsection{Study area}

The study was conducted in the Spanish part of the Iberian Peninsula. Located in southern Europe (latitudinal range of $36.0^{\circ}-43.7^{\circ}$ $\mathrm{N}$ ), it is characterized by a high variability of physiographical conditions. This region is divided in two macrobioclimatic areas (the Temperate and the Mediterranean zone, the latter mainly characterized by strong summer water stress, Rivas-Martínez et al. 2004). The altitudinal range goes from the sea level to $>3,400 \mathrm{~m}$. The diversity of geo-hydrological conditions makes flow regimes of rivers highly variable, from temporary (seasonal flow) to perennial (continuous flow). All of these characteristics provide a high heterogeneity of habitats (from arid steppes to moist fir-beech forest, see Blondel and Vigne, 1993) and together with other Mediterranean basins, they constitute some of the most important hotspot in the world (Myers et al., 2000).

In addition to the diverse physiographical conditions, the Iberian Peninsula presents a wide variety of anthropogenic pressures, from the long history of deforestation related to political and cultural changes and pressures exerted by agriculture and cattle breeding (López-

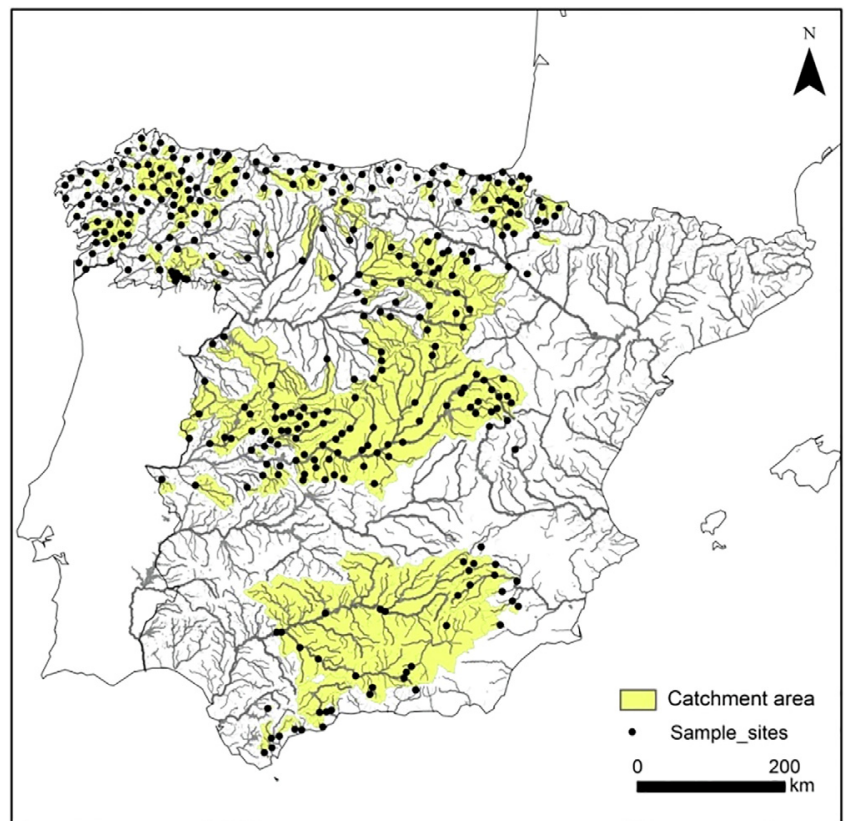

Fig. 1. Location of sample sites in the Iberian Peninsula selected for this study and watershed areas to selected sample sites.

Bermúdez and García-Ruiz, 2008; Cerdá, 2008), to the heterogeneous distribution of human population, from extremely low densities of 9 inhabitants $\mathrm{km}^{-2}$, to high densities of 810 inhabitants $\mathrm{km}^{-2}$, (source: Instituto Nacional de Estadística, http://www.ine.es/).

\subsection{Fish data}

Sample sites were selected from the Spanish section of the database originally collected within the EU EFI+ project (http://efi-plus.boku. ac.at/) with 1741 fishing occasions in 1507 sampling sites. Fish data were sampled by means of electrofishing surveys and determined at species level. Only captures in the first pass were considered since not all fishing occasions had multiple passes. Fish samplings took place between 1991 and 2007 (see Table S1 for a complete list of sampling sites). Length data of every individual were available in the original database (resolution $1 \mathrm{~mm}$ ). A total of 326 sample sites were finally selected from the original database to attain similar sample densities all over the study area (Fig. 1) since some regions as North and Northwest had been more densely represented in the original sampling network than the rest.

\subsection{Geo-climatic and land use descriptors}

All sites were characterized at the catchment scale by means of two anthropogenic descriptors, in addition to seven natural environmental descriptors covering geographical and climatic aspects. CORINE land cover data (European Environmental Agency; www.eea.europa.eu) was used to calculate the proportion of agricultural and urban land within the catchment. Both descriptors were selected because they are known to affect aquatic communities (Allan, 2004; Feld et al., 2013) although the influence degree is still uncertain (Benejam et al., 2016; Feld et al., 2016). The land cover classes that aggregate the type 1 of CORINE level 1 "Artificial surfaces" were considered as "urban land". As "agricultural land" it was considered the type 2 of CORINE level 1, "Agricultural areas", except classes 2.4.3 (Land principally occupied by agriculture, with significant areas of natural vegetation) and 2.4.4. (Agro-forestry areas) due to their higher level of naturalness. Since fish sampling took place between 1991 and 2007 and different CORINE land cover data are available (1990, 2000 and 2006), three sample periods were considered 
Table 1

CORINE land cover versions and climatic period within Spain02 database considered according to sample year.

\begin{tabular}{lll}
\hline Fish sample period & Land use data source & Climatic period used \\
\hline $1991-1993$ & CORINE 1990 & $1960-1990$ \\
$1994-2002$ & CORINE 2000 & $1970-2000$ \\
$2003-2007$ & CORINE 2006 & $1976-2006$ \\
\hline
\end{tabular}

to attribute the closest land cover version in each case (see Table S1): CORINE 1990 for samplings prior 1992, CORINE 2000 for samplings between 1993 and 2002, CORINE 2006 for samplings between 2003 and 2007 (Table 1, Table S1).

Of the seven geo-climatic descriptors, latitude, longitude and altitude were collected from the original database EFI + . The upstream catchment area was derived from digital maps using ArcGIS 10.3 ${ }^{\circledR}$. For temperature related variables, the climatic database Spain02 (see details in Herrera et al. 2012) was used, which comprises monthly temperature data for the period $1950-2008$ in a $0.2^{\circ}$ regular grid. A 30 -year period, prior to the sampling date, was selected to calculate climatic variables for each site. In a similar way to land cover assignation procedure three different periods were used (Table 1, Table S1). From the monthly data base, annual mean temperature was calculated as the average of mean annual temperature along the period. With the aim of considering the frequent high variability along the year and between years in the Iberian Peninsula, coefficients of variation of the temperature along the year $\left(\mathrm{T}_{\text {intra }} \mathrm{CV}\right)$ and along the period $\left(\mathrm{T}_{\text {inter }} \mathrm{CV}\right)$ were calculated.

\subsection{Fish community indices and indicators}

In total, ten fish community metrics were calculated for each sampling site for the entire fish community. It has not been the objective of this study to consider all types of indices or indicators described previously in literature, and thus the indices and indicators considered in this study should be viewed as a sample of some of the most commonly used and we have tried to group them to facilitate the interpretation of results. Among taxonomic indicators, species richness, Shannon index, rareness and taxonomic distinctness were calculated. Species richness describes the total number of different taxa encountered at a site, while Shannon index accounts also for the relative abundance of each species within a site (Shannon, 1948). Taxon rareness provides a measure of the summed relative frequencies of rare taxa within a community, based on the overall frequency of the taxa in the entire dataset (Crisp et al., 2001; Linder, 2001). Taxonomic distinctness describes the phylogenetic connections of the taxa within a community (Clarke and Warwick, 1998). These classical taxonomic indicators have been widely used among ecological assessments, although they have been found to present variable responses to environmental and human disturbance gradients (Benejam et al., 2016; Feld et al., 2016).

Regarding the size-related indicators, from the original database based on lengths $(\mathrm{mm})$ of individuals, individual body weights $(\mathrm{g})$ were estimated by means of length-weight relationships reported in FishBase (www.fishbase.org, Froese and Pauly 2016). Mean weight, total weight range, maximum weight and weight diversity were calculated. Weight diversity was calculated following the non-parametric approach of Quintana et al. (2008). This metric is based on Shannon diversity and integrates the amplitude of the weight range and the evenness as Shannon integrates the number of species and their relative abundance. Size diversity metrics have been found to mirror environmental and human disturbance gradients (Brucet et al., 2006; Emmrich et al., 2011, Benejam et al., 2016).

Finally, two bioassessment fish-based indices were calculated: European Fish Index (EFI+ hereafter) and Fish Region Index (FRI hereafter). The EFI + is a multimetric index designed to assess the human-induced impact on the biotic condition in rivers by measuring the deviation of the actual fish fauna from a predicted fish assemblage for each specific river type using 13 abiotic variables (Pont et al., 2007; $\mathrm{EFI}+$ Consortium, 2009), and thus a priori controlling the effects of geoclimatic variables. On a European scale the EFI+ represents the first fish-based assessment method applicable on a large geographical scale (Logez and Pont, 2011; Segurado et al., 2014). For its calculation free software (available at http://fame.boku.ac.at) was used. The result, ranging from zero (very impaired) to one (reference conditions), provides information about the impaired degree of the site. The FRI (Wolter et al., 2013) is based on previous indices developed and harmonized for Austria (Schmutz et al., 2000) and Germany (Dußling et al., 2004). Based on the natural probabilities of occurrence of every single species in a given sample in the river regions relevant for fish (Epirhithral, Metarhithral, Hyporhitral, Epipotamal, Metapotamal, and Hypopotamal), the FRI is calculated as average of the present species averages with unequal variances and random samples. This kind of fish specific indexes have been less explored and compared with other indexes or indicators in scientific literature, being scarce their application in Mediterranean areas (Segurado et al., 2014).

\subsection{Data analysis}

Spearman correlation matrix was calculated for all geo-climatic and land cover variables with the aim to exclude highly correlated variables, considered as those with a Spearman correlation $>|0.7|$. Spearman correlation was also evaluated between community metrics to assess its relationship. All values were $\ln (x+1)$ transformed to reduce the influence of extreme values. To allow comparing the observed effects of the factors on different fish community metrics, all values were standardized: $x_{s t, I}=\left(x_{i}-\mu\right) / \sigma(x)$, being $x i$ each value of the $\ln$ $(\mathrm{x}+1)$ transformed data base, $\mu$ the average value and $\sigma(\mathrm{x})$ the standard deviation of the $\ln (x+1)$ transformed data base.

The relations between every fish community metric and the selected (uncorrelated) geo-climatic and land cover variables were quantified by means of boosted regression tree analyses (BRT hereafter, Elith et al., 2008), a method that allows to detect potential non-linear responses. A BRT model was fitted for every fish community index or indicator and the selected geo-climatic and land cover variables. Model settings were chosen according to Elith et al. (2008) criteria, setting a learning rate $l r$ slow enough to increase the number of trees required to achieve the lowest predictive deviance up to 1000 . Since the number of observations varies around 250, and accordingly to Elith et al. (2008) recommendations, tree complexity was set at 3 to allow us to test 3-way interactions, bag fraction was set at 0.5 , using 5 -fold cross validation. For the model analysis and visual interpretation of the shape of response (partial dependence plots), we used an approach similar to Wagenhoff et al. (2017) calculating total deviance explained (TDE) as (\%TDE $=[$ mean total deviance - mean residual deviance $] /$ mean total deviance). Moreover, we identified thresholds of interest along geoclimatic gradients, such as abrupt changes in the metric response to gradual changes in a geo-climatic variable, and along stressor gradients, such as impact cessation point (i.e., last change of a positive or a negative response rate to no stressor influence) or abrupt changes (i.e., special case when impact initiation matches impact cessation). The relative position of this thresholds in the stressor range of variation would indicate the sensitiveness of the metric to that specific stressor (i.e. the lower the stressor value to initiate the metric response, the higher the sensitiveness of the metric to that stressor).

To allow comparing the strength of the response to variables across models, the absolute contribution of each variable to the total deviance has been calculated as relative contribution $\times \% T D E$. By this way, it is possible to compare contributions even if the models result in very different explicative power.

All the analyses were conducted using R v. software ( $\mathrm{R}$ Development Core Team 2017). The function cor.test of package "stats" and the 
Table 2

Range of variation of geo-climatic and anthropogenic descriptors, coefficient of variation (\%) and descriptors used to proceed with the standardization $\left[\mathrm{x}_{\mathrm{st}, \mathrm{I}}=\left(\mathrm{x}_{\mathrm{i}}-\mu\right) / \sigma(\mathrm{x})\right]$ of $\operatorname{Ln}(\mathrm{x}+1)$ transformed data base: $\mu$ is the average value and $\sigma(\mathrm{x})$ is the standard deviation of the $\operatorname{Ln}(\mathrm{x}+1)$ transformed data base.

\begin{tabular}{|c|c|c|c|c|}
\hline Descriptor & Code & $\begin{array}{l}\text { Range } \\
\text { (min; max) }\end{array}$ & CV (\%) & $\mu ; \sigma(\mathrm{x})$ \\
\hline \multicolumn{5}{|l|}{ Geo-climatic } \\
\hline Latitude $\left({ }^{\circ}\right)$ & Lat & $36.21 ; 43.65$ & 4.57 & $3.75 ; 0.05$ \\
\hline Longitude $\left({ }^{\circ}\right)$ & Lon & $-0.89 ;-9.12$ & 45.30 & $1.70 ; 0.41$ \\
\hline Altitude (m.a.s.l.) & Alt & $1 ; 1650$ & 67.89 & $5.80 ; 1.29$ \\
\hline Catchment area (ha) & Cat & $\begin{array}{l}342.5 \\
4,139,000\end{array}$ & 385.19 & $9.60 ; 1.82$ \\
\hline $\begin{array}{l}\text { Mean annual air temperature } \\
\quad\left({ }^{\circ} \mathrm{C}\right)\end{array}$ & Temp & $7.45 ; 17.87$ & 18.38 & $2.57 ; 0.17$ \\
\hline Interannual CV temperature & TinterCV & $3.0 ; 14.0$ & 28.92 & $0.06 ; 0.02$ \\
\hline Intra-annual CV temperature & TintraCV & $22.0 ; 84.0$ & 25.02 & $0.39 ; 0.08$ \\
\hline \multicolumn{5}{|l|}{ Anthropogenic } \\
\hline Agriculture land (\%) & $\mathrm{Ag}$ & $0 ; 95.3$ & 112.67 & $0.15 ; 0.15$ \\
\hline Urban land (\%) & Ur & $0 ; 21.3$ & 306.56 & $0.01 ; 0.02$ \\
\hline
\end{tabular}

*Note: $\mu$ is the average value and $\sigma(\mathrm{x})$ is the standard deviation of the $\ln (\mathrm{x}+1)$ transformed data base.

function gbm.step of package "dismo" (Hijmans et al., 2017) were used to run the Spearman correlation test and the BRT analysis respectively.

\section{Results}

\subsection{Characterization and correlation of geo-climatic variables and indices/} indicators

Differences in range and coefficient of variation (CV) were remarkable for geo-climatic and anthropogenic descriptors that characterize selected sites (Table 2). The highest variability occurred in catchment area, agriculture land and urban land ( $>100 \%$ in all cases). Intermediate variabilities were found for altitude and interannual CV of temperature; altitude of sampled sites ranged from almost the sea level $(1 \mathrm{~m})$ to $1650 \mathrm{~m}$ and interannual $\mathrm{CV}$ of temperature ranged from 3 to $14 \%$. Thus, studied sites present a wide variety of conditions. Except for the geographic coordinates, the lowest variability was found for mean annual air temperature and intra-annual CV temperature. Two of the geo-climatic variables (altitude and Intra-annual CV temperature) were significantly correlated (Spearman test, $\mathrm{p}<0.05,|\mathrm{r}|>0.7$ ) with temperature (Table 3), thus in the subsequent statistical analysis these variables (both altitude and Intra-annual CV temperature) were not included and temperature variable was preserved as climatic variable.

Several community indices and indicators were also correlated (Spearman test, $\mathrm{p}<0.05$, Table 4). With the exception of Distinctness, taxonomic indicators were highly positively correlated between them $(\mathrm{r}>0.75, \mathrm{p}<0.001)$, weakly negatively correlated with EFI+

Table 3

Correlation matrix of the geo-climatic and anthropogenic descriptors: longitude (Lon), latitude (Lat), altitude (Alt), temperature (Temp), interannual CV temperature (TinterCV), intra-annual CV temperature (TintraCV), Agricultural land (Ag), Urban land (Ur). Significant correlations $>|0.7|$ are displayed in bold type.

\begin{tabular}{|c|c|c|c|c|c|c|c|c|}
\hline & Lon & Alt & Cat & Temp & TinterCV & TintraCV & $\mathrm{Ag}$ & Ur \\
\hline Lat & -0.2 & -0.2 & -0.3 & -0.5 & -0.2 & -0.1 & -0.2 & -0.0 \\
\hline Lon & & 0.4 & 0.0 & -0.1 & -0.0 & 0.4 & -0.0 & 0.1 \\
\hline Alt & & & -0.1 & -0.7 & 0.5 & 0.9 & -0.1 & -0.1 \\
\hline Cat & & & & 0.3 & -0.1 & -0.1 & 0.3 & 0.1 \\
\hline Temp & & & & & -0.4 & -0.7 & 0.3 & 0.2 \\
\hline TinterCV & & & & & & 0.5 & -0.2 & -0.2 \\
\hline TintraCV & & & & & & & -0.1 & -0.1 \\
\hline $\mathrm{Ag}$ & & & & & & & & 0.1 \\
\hline
\end{tabular}

( $\mathrm{r}<|0.5|, \mathrm{p}<0.001)$ and positively correlated with FRI $(\mathrm{r}>0.6$, $\mathrm{p}<0.001$ ). This later relation is rather counterintuitive, since FRI normally increases while RI, SW and RA decrease with impairment. As a matter of fact, FRI increases with impairment within a given fish region in the gradient epirhithral-metapotamal; but also increases among fish regions in that gradient. Size related indicators also exhibited a high positive correlation within them ( $r>0.69$, $p<0.001$ ), but scarcely correlated with other types of metrics (although significant, $\mathrm{p}<0.01, \mathrm{r} \leq 0.22$ in the case of taxonomic indicators, and $r<|0.3|$ in the case of multimetric indices). Finally, multimetric indices were weakly correlated between them $(r=-0.48, p<0.001)$ and, as expected, in a negative way as more impaired sites present higher values of FRI and lower values of EFI+. Therefore, metrics within a given type (taxonomic, size related and multimetric) provide redundant information (all indices or indicators within the same group are well correlated, $\mathrm{r}>0.69, \mathrm{p}<0.001$ ) with the exception of Distinctness and multimetric indices given that they are weakly correlated.

The range and the coefficient of variation (CV) were also substantial for indices and indicators (Table 5). In general, size related indicators (with the exception of Size Diversity) present the highest variability together with rareness (CV $>170 \%$ ), while multimetric indices exhibited low variability together with distinctness (CV $<30 \%$ ). Therefore, the wide variety of geo-climatic and anthropogenic descriptors offered a remarkable context to deal with the hypothesis.

\subsection{BRT models: strength, sign and shape of the response}

All BRT models explained $>25 \%$ of the total deviance (Table 6 ) and five of the ten BRT models explained $\geq 50 \%$ of the total deviance. The model fitted to FRI exhibited the highest goodness-of-fit (78.4\% TDE). Taxonomic indicators models, such as those resulting from richness, Shannon and distinctness explained $\sim 60 \% \mathrm{TDE}$, and performed better than those referred to size-related indicators which explained roughly half that amount ( $\sim 30 \%$ to $40 \% \mathrm{TDE})$. EFI+ yielded intermediate values of \%TDE ( $49.5 \% \mathrm{TDE})$. The predictive performance was the lowest for rareness and size diversity model explaining 26.5 and $27.6 \%$ TDE respectively.

In relative terms, the proportion of variance jointly attributable to geo-climatic descriptors is higher than $65 \%$ TDE in all cases, arising values of $84.1 \% ; 86.2 \% ; 88.1 \%$ and $88.7 \%$ in the case of distinctness, FRI, Shannon and richness respectively (Table 6). Latitude and/or longitude together with catchment area explained a considerable proportion of variance in many community descriptors models. For example, in seven out of ten BRT models, catchment area was the strongest geo-climatic variable with a relative contribution to the model higher than $22 \%$, arising a contribution of $28.8 \%$ in the case of richness. Latitude presented a relative contribution higher than $20 \%$ in five out of ten models, and longitude was the strongest geo-climatic variable in the case of rareness $(23.9 \%)$ and distinctness $(23.5 \%)$. Temperature explained around $25 \%$ of TDE in the case of rareness and FRI, being relevant in three taxonomic indicators while less relevant for size related indicators (relative contribution lower than 11\%). In absolute terms, geo-climatic descriptors have a stronger effect in the case of FRI (67.5\%), Shannon $(54.6 \%)$ and richness and distinctness $(\sim 52 \%)$, while these contributions decrease below $30 \%$ in the case of size related indicators (Table 6).

The jointly contribution of anthropic drivers was lower than geoclimatic drivers, although variedly (Table 6): strength of anthropic drivers was up to eight times less than geo-climatic drivers when explaining richness and Shannon indicators, between four and six times less when explaining rareness, total range, distinctness and FRI; and a half or a third less when explaining EFI + and size related indicators (except total range).

In seven out of the ten models, one single land cover contributes more markedly to the total deviance explained than the other (Table 6). Agriculture land contributes more markedly in the case of richness, 
Table 4

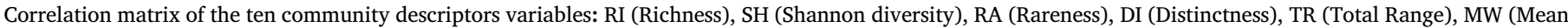

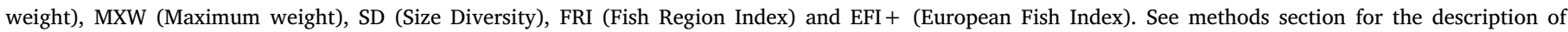
community descriptors. Significant correlations $>0.6$ are displayed in bold type.

\begin{tabular}{|c|c|c|c|c|c|c|c|c|c|}
\hline & SH & RA & DI & TR & MW & MXW & SD & FRI & $\mathrm{EFI}+$ \\
\hline RI & $0.92^{* * *}$ & $0.83^{* * *}$ & $-0.39^{* * *}$ & $0.21 * *$ & $-0.13 \mathrm{~ns}$ & $0.19^{* *}$ & $0.11^{*}$ & $0.63^{* * *}$ & $-0.41 * * *$ \\
\hline SH & & $0.77^{* * *}$ & $-0.367^{* * *}$ & $0.134^{*}$ & $-0.13^{*}$ & $0.12^{*}$ & $0.08 \mathrm{~ns}$ & $0.62^{* * *}$ & $-0.41 * * *$ \\
\hline RA & & & $0.50 * * *$ & $0.10 \mathrm{~ns}$ & $-0.18^{* *}$ & $0.09 \mathrm{~ns}$ & $0.04 \mathrm{~ns}$ & $0.83^{* * *}$ & $-0.41 * k *$ \\
\hline DI & & & & $0.06 \mathrm{~ns}$ & $0.22^{* *}$ & $0.07 \mathrm{~ns}$ & $0.07 \mathrm{~ns}$ & $-0.49 * * *$ & $0.09 \mathrm{~ns}$ \\
\hline TR & & & & & $0.69 * * *$ & $0.72^{* * *}$ & $0.73^{* * *}$ & $-0.16^{* *}$ & $-0.31 * * *$ \\
\hline MW & & & & & & $0.99 * * *$ & $0.90^{* * *}$ & $0.05 \mathrm{~ns}$ & $-0.15 \mathrm{~ns}$ \\
\hline MXW & & & & & & & $0.91 * * *$ & $0.05 \mathrm{~ns}$ & $-0.15^{*}$ \\
\hline SD & & & & & & & & $0.01 \mathrm{~ns}$ & $-0.12 \mathrm{~ns}$ \\
\hline FRI & & & & & & & & & $-0.48 * * *$ \\
\hline
\end{tabular}

Note: Significance after Spearman test $(\mathrm{P}<0.05)$ : *** $\mathrm{P}<0.001$, ** $\mathrm{P}<0.01, * \mathrm{P}<0.05$, n.s. non-significant.

Table 5

Range of variation of community metrics and indicators, coefficient of variation (\%) and descriptors used to procced with the standardization $\left[x_{s t, I}=\left(x_{i}-\mu\right) /\right.$ $\sigma(x)]$ of $\operatorname{Ln}(x+1)$ transformed data base: $\mu$ is the average value and $\sigma(x)$ is the standard deviation of the $\operatorname{Ln}(x+1)$ transformed data base.

\begin{tabular}{lllll}
\hline Community metric & Code & Range (min; max) & CV (\%) & $\mu ; \sigma(\mathrm{x})$ \\
\hline Taxonomic indicators & & & & \\
Richness & RI & $1 ; 8$ & 58.99 & $1.20 ; 0.42$ \\
Shanon diversity & SH & $0 ; 2.45$ & 89.76 & $0.48 ; 0.40$ \\
Rareness & RA & $0 ; 1.03$ & 230.30 & $0.05 ; 0.10$ \\
Taxonomic distinctness & DI & $1 ; 4$ & 22.5 & $1.43 ; 0.19$ \\
Size-related indicators & & & & \\
Total range (mm) & TR & $0 ; 5081.1$ & 171.34 & $4.85 ; 1.36$ \\
Mean weight (g) & MW & $0.31 ; 1516.1$ & 253.28 & $3.19 ; 1.07$ \\
Max weight (g) & MXW & $0.31 ; 5082.10$ & 170.12 & $4.92 ; 1.26$ \\
Size diversity & SD & $0 ; 7.05$ & 41.64 & $1.42 ; 0.52$ \\
Multimetric indexes & & & & \\
EFI index & EFI & $1 ; 0$ & 29.93 & $1.77 ; 0.19$ \\
Fish Region Index & FRI & $3.75 ; 7.99$ & 22.90 & $0.53 ; 0.15$ \\
\hline
\end{tabular}

Shannon, rareness and size diversity indicators, being the latter the most noticeable case with agriculture land explaining 2.7 times as much deviance as the urban land; while the influence of urban land is higher than agriculture in the case of distinctness, mean weight and EFI+, being the latter the most differentiated explaining 2.8 times as much as deviance as agriculture land. Both land uses present similar contribution to the total deviance explained of models in the rest of cases (i.e., for total range, maximum weight and FRI). Taking into account the absolute explained variance by each variable, calculated as relative contribution $\times \% T D E$ (see methods section); it is possible to compare variables contribution between models. Size diversity, FRI and maximum weight are the most sensible to agriculture land, being the absolute contribution of this variable $6.7 ; 5.4$ and $5.0 \%$ to the total deviance. In the case of urban land, the most sensible were EFI+, mean weight, distinctness and FRI being the urban land contribution to the models 10.5 , 8.8; 5.7 and 5.5\%. FRI is the only index whose sensitiveness to both agricultural and urban land-use is higher than $5 \%$ in absolute terms, which could indicate that FRI is a good candidate index to measure both land-use effects on stream fish communities, although $\mathrm{EFI}+$, mean weight and size diversity could be better when analysing an specific single land type.

Indicators and indices respond rather consistently to land-use

Table 6

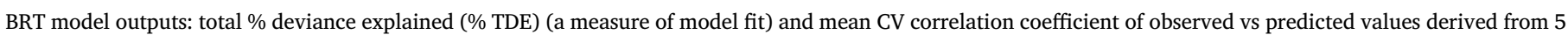

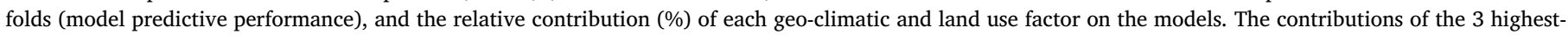

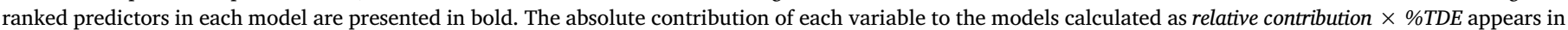

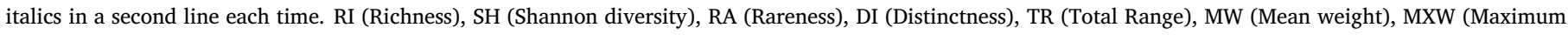
weight), SD (Size Diversity), FRI (Fish Region Index) and EFI+ (European Fish Index).

\begin{tabular}{|c|c|c|c|c|c|c|c|c|c|}
\hline \multirow[b]{2}{*}{ Index } & \multirow[b]{2}{*}{$\operatorname{TDE}(\%)$} & \multirow[b]{2}{*}{ CV correlation } & \multicolumn{7}{|c|}{ Relative contributions of descriptors } \\
\hline & & & Lat & Lon & Catch & $\mathrm{T}$ & TinterCV & $\mathrm{Ag}$ & $\mathrm{Ur}$ \\
\hline \multirow[t]{2}{*}{ RI } & 59.2 & 0.55 & 20.0 & 14.6 & 28.8 & 15.6 & 9.1 & 7.4 & 4.6 \\
\hline & & & 11.8 & 8.6 & 17.1 & 9.2 & 5.4 & 4.4 & 2.7 \\
\hline \multirow[t]{2}{*}{ SH } & 61.5 & 0.61 & 22.1 & 13.2 & 26.3 & 19.0 & 8.1 & 7.4 & 3.8 \\
\hline & & & 13.6 & 8.1 & 16.2 & 11.7 & 5.0 & 4.6 & 2.4 \\
\hline \multirow[t]{2}{*}{ RA } & 26.5 & 0.35 & 5.9 & 23.9 & 15.9 & 24.7 & 9.1 & 13.4 & 7.2 \\
\hline & & & 1.6 & 6.3 & 4.2 & 6.5 & 2.4 & 3.5 & 1.9 \\
\hline \multirow[t]{2}{*}{ DI } & 62.0 & 0.55 & 21.5 & 23.5 & 19.3 & 9.9 & 9.9 & 6.8 & 9.2 \\
\hline & & & 13.3 & 14.6 & 12.0 & 6.2 & 6.1 & 4.2 & 5.7 \\
\hline \multirow[t]{2}{*}{ TR } & 34.2 & 0.32 & 21.9 & 15.7 & 26.0 & 7.1 & 8.3 & 11.1 & 9.9 \\
\hline & & & 7.5 & 5.4 & 8.9 & 2.4 & 2.8 & 3.8 & 3.4 \\
\hline \multirow[t]{2}{*}{ MW } & 41.1 & 0.31 & 11.9 & 11.8 & 24.4 & 10.9 & 8.9 & 10.7 & 21.3 \\
\hline & & & 4.9 & 4.9 & 10.0 & 4.5 & 3.7 & 4.4 & 8.8 \\
\hline \multirow[t]{2}{*}{ MXW } & 39.4 & 0.37 & 17.2 & 16.9 & 24.8 & 7.4 & 8.3 & 12.7 & 12.8 \\
\hline & & & 6.8 & 6.6 & 9.8 & 2.9 & 3.3 & 5.0 & 5.0 \\
\hline \multirow[t]{2}{*}{ SD } & 27.6 & 0.24 & 20.5 & 12.1 & 19.2 & 7.0 & 7.9 & 24.3 & 9.1 \\
\hline & & & 5.7 & 3.3 & 5.3 & 1.9 & 2.2 & 6.7 & 2.5 \\
\hline \multirow[t]{2}{*}{ FRI } & 78.4 & 0.78 & 14.7 & 15.5 & 23.4 & 24.5 & 8.1 & 6.9 & 7.0 \\
\hline & & & 11.5 & 12.1 & 18.4 & 19.2 & 6.3 & 5.4 & 5.5 \\
\hline \multirow[t]{2}{*}{$\mathrm{EFI}+$} & 49.5 & 0.35 & 15.0 & 16.4 & 22.0 & 7.2 & 10.6 & 7.6 & 21.2 \\
\hline & & & 7.41 & 8.10 & 10.91 & 3.55 & 5.25 & 3.76 & 10.51 \\
\hline
\end{tabular}



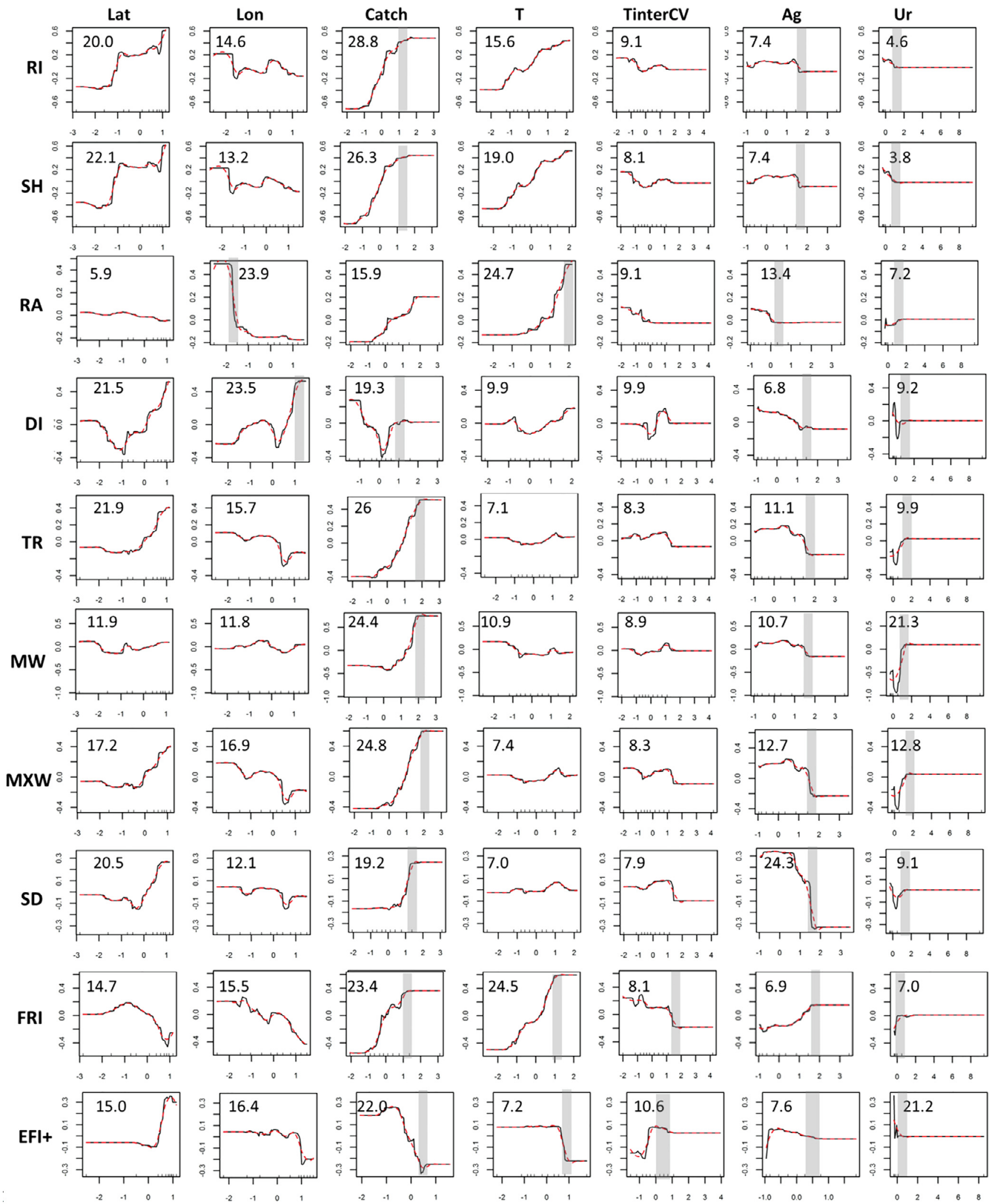

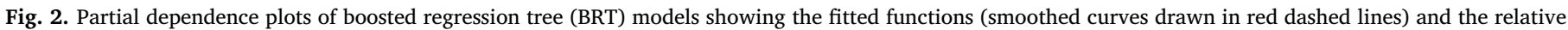

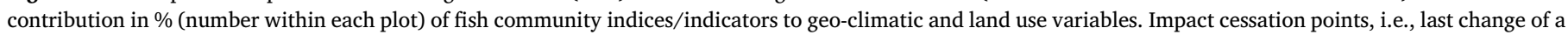
positive or a negative response rate to no stressor influence, are indicated by a shaded grey area when they are patent. 
variables (Fig. 2). Indices that penalize the more impaired conditions used to show a negative response to urban and agricultural area in the catchment, whereas FRI, which increases with impact intensity, responds positively. Most of indices and indicators respond to extremely low values of urban land proportion, and the impact cessation point, i.e., the stressor intensity where community metric stabilizes, is reached around 2.7\% (1 standardized unit in Fig. 2, hereafter st. unit), even less in the case of FRI and EFI+ being around 1.2\% (0.25 st. unit). This evidences that they become saturated by very low values of urban area in the catchment. However until reaching that cessation point, the response pattern of indices and indicators is variable. Richness, Shannon and EFI + exhibited a decreasing trend, i.e., the higher the pressure, the lower the values of indices and indicators until reach that early saturation point. Meanwhile, the rest of indicators and indices, seem to experience an inflection point meaning that very low values, around $1.7 \%$ ( 0.5 st. unit) of urban land proportion has a positive effect in the indices and indicators values.

On the contrary, agriculture land proportion induces a similar response in most of the metrics presenting relatively high values when agricultural land proportion is very low, and subsequently decreasing more or less sharply arising a stable value when pressure increase (i.e., impact cessation point) (Fig. 2). Some metrics present an abrupt change at variable values depending on the metric, e.g., around 50.8\% (1.75 st. unit) in the case of richness, Shannon, total range, mean weight, maximum weight and size diversity, and around $15.7 \%$ ( 0.5 st. unit) for rareness. Exceptions to this pattern are distinctness and FRI which present a gradual decrease and a gradual increase respectively until reach the saturation point around $45.2 \%$ (1.5 st. unit) and 50.8\% (1.75 st. unit) respectively; and EFI + that present an abrupt increase with lower values of agricultural land until reach $2.5 \%$ (-0.75 st. unit) and then slightly decrease.

Independently of land-use, geo-climatic factors induce the strongest responses on fish community indices and indicators (Table 6). Except in the case of distinctness and EFI+, most of indices exhibited a gradual positive relation with catchment area throughout a wide range of values (between $24 \mathrm{~km}^{2}$ ( -1 st. unit) and $5605 \mathrm{~km}^{2}$ ( 2 st. unit), and in the case of size diversity an abrupt positive change around $900 \mathrm{~km}^{2}$ (1 st. unit) is found. Latitude induces similar responses for most of the indices and indicators with higher values at higher latitudes, except for FRI that present a negative response and for rareness and mean weight where no clear response is found. Longitude effect is more variable across fish community metrics (Fig. 2). The strongest effect is found for rareness where a negative relation is observed presenting an abrupt change around $-1.9^{\circ} \mathrm{E}$ ( -1.5 st. unit). Negative responses are also found for richness, Shannon, total range, maximum weight, FRI and EFI + although exhibiting varied shapes. In the case of temperature, a clear relation is found for those community metrics where the relative contribution of temperature is higher than $15 \%$, positive for richness, Shannon, rareness and FRI, and negative for EFI +, while the shape is fuzzier where a poorer relation exist, i.e., for size-related variables and distinctness.

\section{Discussion}

As hypothesized, we found that fish community metrics respond rather consistently to anthropogenic land cover proportion, i.e., community metrics reflect a poorer status when land cover proportion in the catchment increase. Moreover, geo-climatic variables induce the most noticeable responses on fish community as found by previous authors (Brucet et al., 2013; Marzin et al., 2013; Feld et al., 2016), who have highlighted the relevance of environmental conditions in the response of ecological indicators.

\subsection{Strength, sign and shape of the response to land use gradients}

Among the anthropic drivers, the strength of the response of agricultural land proportion used to be similar or higher than urban land proportion, except in the case of distinctness, mean weight and EFI + where urban land proportion contributed more to explained variance. Both agricultural and urban land uses produced a response on the tested metrics that was consistent with their consideration as anthropogenic stressors. The sign of the responses to urban and agricultural land uses are also consistent with previous comparable studies. Fish community richness and diversity have been frequently reported to negatively respond to agricultural and urban land use (Burcher et al., 2007; Clapcott et al., 2012; Benejam et al., 2016). However, this is controversial since some other studies concluded that the response might be lacking (Marzin et al., 2012). Even a positive response of richness and taxonomic rareness to agricultural land use has been reported for fish (Feld et al., 2016). In our study, richness and Shannon diversity slightly increase with increasing agricultural land use proportion at low values of this stressor. This might be due to the inclusion of alien species in the calculation of these indexes. Some of these species will benefit from impacts derived from agricultural land use in the catchment (Cooper et al., 2013). For instance, crucian carp (Carassius carassius) and common carp (Cyprinus carpio) would tolerate eutrophy related deoxygenation (Jeppesen et al., 2010), and have in reservoirs and regulated reaches a focus of invasions and habitat refuge.

In the case of body size based metrics, we have found a stronger effect of agricultural land proportion on all size related metrics than urban land, with larger values of size related metrics in less degraded catchments. This results are consistent with previous authors (Emmrich et al., 2011; Maceda-Veiga et al., 2018), but the opposite relation for size diversity and total range has been also detected (Murphy et al., 2013; Benejam et al., 2016). Larger body size is frequently related to higher trophic levels, which is the basis for hypothesis linking larger sizes to large food chains and, consequently, less impaired conditions. But some clade-specific adaptations to herbivory (e.g., Cyprinids, see Burress et al., 2016), along with the existence of large bodied tolerant species (e.g., certain catfish species, see Benejam et al., 2016), may add regional variations to such generalization; thus producing regional deviations from what could be expected. Regarding to multimetric indices, it had been found that overall fish biotic metric (FAME) at basin scales have a weaker response to perturbation in Mediterranean regions (Ferreira et al., 2007). However, EFI+ (an extension of the original FAME) was improved using a greater Spanish fish data. FRI was developed in Austria and not harmonized for Spain, although its scientific basis were applied to Spanish fish communities in the past (García de Jalón and González del Tánago, 1983). In our case, both indices responded accordingly to their purpose; although FRI responded similarly to both types of land use and EFI + responded more markedly to urban land use. EFI + has been tested as a sensitive metric to detect both global and specific stressors (Marzin et al., 2012; Almeida et al., 2017).

In general, fish community responses to land use, as an anthropogenic stressor, have been frequently reported as weak (Brucet et al., 2013), or at least weaker than other biological quality elements (Clapcott et al., 2012; Dahm et al., 2013; Kail and Wolter, 2013). This weaker response may be caused by the higher mobility of fish relative to other taxa. The existence of accessible favourable habitats would buffer the effect of perturbations, and the responses of the metrics would remain undetected (Marzin et al., 2012). In that sense, a scaledependent analysis considering also hydromorphodynamic drivers of biological communities acting at lower spatial-scale (e.g., reach or segment scale), such as channel features, riparian vegetation structure, upstream river network characteristics considering the presence of barriers could greatly contribute to a better comprehension of fish community responses. More extensive data sets could also include a higher resolution of land use types to identify the key specific artificial land covers that affect fish communities more intensely. 


\subsection{Non-linear responses along the stressor gradients}

The analysis of the shape of the response curve has allowed us to detect how anthropic and geo-climatic variables affect each fish community metric, identifying thresholds of interest along the variable gradient. The technique used for this purpose (BRT) has been tested in previous similar studies and has been proven to give substantial predictive advantage over methods such as GLM and GAM (Elith et al., 2008), and even over specific techniques like piecewise linear regression models (Wagenhoff et al., 2017). At this respect, the proportion of agricultural land induces a similar response in most of the community metrics presenting higher values at less degraded catchment and exhibiting abrupt changes more or less sharply over a wider range of proportions, while urban land effects appear at very low values of its proportion, which becomes rapidly saturated. In some cases, as in rareness, distinctness, total range, mean weight, maximum weight and size diversity, very low values (around 1.7\%) of urban land proportion has a positive effect in the indices and indicators values. This kind of positive effect at low pressure values has been previously described, e.g., initial increase of nutrients or sediments had a positive effect on ecological attributes (Odum et al., 1979), such as an increase in macroinvertebrate production and diversity (Wagenhoff et al., 2011, 2012). This early response at so low values makes the effect of the urban area very difficult to quantify, beyond determining whether it affects (totally) or not (at all). Therefore, the effect of an increase in the agricultural area is easier to quantify, and makes agricultural land a pressure whose impacts on the fish community are easier to modulate by planners than impacts caused by urban land use. FRI is the metric that is globally more sensitive to the two types of land uses considered. Both cause an increase in the value of FRI, which is consistent with the response of this index to the impoverishment of the ecological conditions (Kail and Wolter, 2013; Wolter et al., 2013).

Many evidences of a non-linear effect with very low thresholds of initiation (10-20\%) are collected in Allan (2004), and are considered as one of the characteristics of the effect of the impervious area, as a consequence of the increment of urban land use on stream biota. We have seen that the most sensitive metrics to this pressure (which are EFI + , mean weight, FRI, and maximum weight) show an equally nonlinear and abrupt response, starting at low values and producing a saturation of the response (impact cessation threshold) at values around $3 \%$. In the case of agriculture land the response is more gradual obtaining a saturation of the response at values close to $50 \%$. This observed range is highly consistent with those compiled (30\%-50\%) by Allan (2004) in New Zealand and United States watersheds.

\subsection{Strength, sign and shape of the response to geo-climatic gradients}

As expected from literature review, geo-climatic variables were noticeably more influential than land use variables and different shapes of response were found across the different community metric here considered. Taxonomic based indicators, except distinctness, show a direct positive response to catchment area. This somewhat expectable since the size of the basin increases along the river continuum (Vannote et al., 1980); and species diversity increases from the heterotrophic upper tributaries to the autotrophic middle sections, where diversity usually reaches a maximum. In the lower reaches the river becomes heterotrophic again, and the number of species becomes reduced. However, all the sampling sites in this study were located in wadeable sections, far upstream from those lower reaches. Regarding body size related indicators, they are quite sensitive to catchment area and latitude according to our results, showing a positive response in most of cases. This is to some extent expectable since, at similar hydrological conditions, micro and mesohabitat characteristics vary with the catchment area, producing a more suitable habitat to larger fish (i.e., reduced water velocity and increased channel depth). Both multimetric indices, FRI and EFI+, are also highly dependent on geo-climatic variables. EFI + could be expected to be almost independent of geoclimatic variables, since it was designed to be applicable in all Europe (Logez and Pont, 2011). During the process of data input in the software to calculate this index, longitude, latitude, upstream drainage area, and mean air temperature of the sampled site are required. However, latitude, longitude, catchment area and interannual variability of temperature account a no negligible ( $>10 \%$ ) proportion of TDE in the EFI + model. This index increases abruptly with latitude and decreases gradually with catchment area, which could be related with the normally lesser extension and better ecological status of rivers in the North relative to the South of the Spanish surface water bodies (WISE WFD Database https://www.eea.europa.eu/data-and-maps/data/wise-wfd). In the case of FRI, it is an index that increases along the gradient rhithral-pothamal conditions, and for a given river region, increases with increasing impact (Wolter et al., 2013). Latitude and longitude induce gradual changes in FRI over a wide range of values. At higher latitudes the value of the FRI decreases, which is understandable, since at higher latitudes in the Iberian Peninsula rivers source closer to their mouth, without generating lower reaches with potamal conditions. There is also an associated boreo-alpine gradient by which latitude compensates the rhithral-potamal gradient caused by altitude. Longitude induces a similar response: the farther west the lower the value of FRI. Longitude apparently should not produce an effect on the rhithral-potamal conditions of streams, unless sites are not equally located along that gradient in the dataset. Including sites in Portugal (Fig. 1) would correct the over-representation of the northwest of the Iberian Peninsula (with short streams and rhithral conditions) relative to the southwest (long rivers with abundant potamal reaches).

The present study contributes to the understanding of the effects of stressors acting at large scales (i.e., catchment scale) on fish communities by analysing a set of the most frequently used metrics in stream health assessment studies. The combination of taxonomic classic indicators, with size related indicators, which are novel in lotic ecosystems, and also recent fish specific multimetric indices created in the European context (WFD) could be effective tools to evaluate the impact of land use changes as they show different sensitiveness to different values of geo-climatic conditions and stressor levels. Therefore, we would recommend combining all these types of metrics to build an efficient array of indicators to be used in the same way physicians employ a diagnosis toolbox (Elosegi et al., 2017). This 'river doctor diagnosis toolbox' should not include redundant indicators such as those highly correlated to each other (e.g., all the taxonomic indicators); selecting the ones that are most sensitive to stressors and independent of geo-climatic variables. Further advances on this approach should come from testing other currently used indicators. Moreover, the combination with cause-effect approaches to elucidate mechanistic ecosystem functioning, could be of paramount importance contributing to conservation and restoration goals and anticipating management initiatives, given the incessantly alteration at the landscape scale worldwide with relevant implications for biodiversity monitoring.

\section{Acknowledgements}

The authors thank project EFI+ (European Commission under the Sixth Framework Programme, contract number 044096), and the many field biologists, too numerous to mention, that provided the fish data for that project. The authors thank AEMET and UC for the data provided for this work (Spain02v5 dataset, available at http://www.meteo.unican.es/datasets/spain02). VMF was supported by a research grant awarded by the Spanish Government (Becas de Formación del Profesorado Universitario). We thank Javier Herranz for his help in the initial selection of sites. The coments by two anonymous referees on an earlier version of this manuscript are gratefully acknowledged. 


\section{Appendix A. Supplementary data}

Supplementary data to this article can be found online at https:// doi.org/10.1016/j.ecolind.2019.04.076.

\section{References}

Allan, J.D., 2004. Landscapes and riverscapes: the influence of land use on stream ecosystems. Annu. Rev. Ecol. Evol. Syst. 35, 257-284.

Almeida, D., Alcaraz-Hernández, J.D., Merciai, R., Benejam, L., García-Berthou, E., 2017. Relationship of fish indices with sampling effort and land use change in a large Mediterranean river. Sci. Total Environ. 605, 1055-1063.

Aparicio, E., Carmona-Catot, G., Moyle, P.B., García-Berthou, E., 2011. Development and evaluation of a fish-based index to assess biological integrity of Mediterranean streams. Aquat. Conserv. 21 (4), 324-337.

Benejam, L., Teixeira-de Mello, F., Meerhoff, M., Loureiro, M., Jeppesen, E., Brucet, S., 2016. Assessing effects of change in land use on size-related variables of fish in subtropical streams 1. Can. J. Fish. Aquat. Sci. 73 (4), 547-556.

Birk, S., Bonne, W., Borja, A., Brucet, S., Courrat, A., Pokane, S., Solimini, A., vande Bund, W., Zampoukas, N., Hering, D., 2012. Three hundred ways to assessEurope's surface waters: an almost complete overview of biological methods toimplement the Water Framework Directive. Ecol. Indic. 18, 31-41.

Blevins, Z.W., Effert, E.L., Wahl, D.H., Suski, C.D., 2013. Land use drives the physiological properties of a stream fish. Ecol. Ind. 24, 224-235.

Blondel, J., Vigne, J.D., 1993. Space, time, and man as determinants of diversity of birds and mammals in the Mediterranean region. In: Ricklefs, R.E., Schluter, D. (Eds.), Species Diversity in Ecological Communities. Univ Chicago Press, Chicago, pp. 135-146.

Bonada, N., Prat, N., Resh, V.H., Statzner, B., 2006. Developments in aquatic insect biomonitoring: a comparative analysis of recent approaches. Annu. Rev. Entomol. 51, 495-523.

Brucet, S., Boix, D., López-Flores, R., Badosa, A., Quintana, X., 2006. Size and species diversity of zooplankton communities in fluctuating Mediterranean salt marshes. Estuar. Coast. Shelf Sci. 67, 424-432.

Brucet, S., Pédron, S., Mehner, T., Lauridsen, T.L., Argillier, C., Winfield, I.J., Volta, P., Emmrich, M., Hesthagen, T., Holmgren, K., Benejam, L., 2013. Fish diversity in European lakes: geographical factors dominate over anthropogenic pressures. Freshwater Biol. 58 (9), 1779-1793.

Burcher, C.L., Valett, H.M., Benfield, E.F., 2007. The land-cover cascade: relationships coupling land and water. Ecology 88 (1), 228-242.

Burress, E.D., Holcomb, J.M., Bonato, K.O., Armbruster, J.W., 2016. Body size is negatively correlated with trophic position among cyprinids. R. Soc. Open Sci. 3 (5), 150652.

Carballo, R., Cancela, J.J., Iglesias, G., Marín, A., Neira, X.X., Cuesta, T.S., 2009. WFD indicators and definition of the ecological status of rivers. Water Resour. Manage. 23 (11), 2231-2247.

Casatti, L., Ferreira, C.P., Langeani, F., 2009. A fish-based biotic integrity index for assessment of lowland streams in southeastern Brazil. Hydrobiologia 623 (1), 173-189.

Cerdá, A. (Ed.), 2008. Erosión y degradación del suelo agrícola en España. Universitat de Valencia, Cátedra Divulgación de la Ciencia.

Clapcott, J.E., Collier, K.J., Death, R.G., Goodwin, E.O., Harding, J.S., Kelly, D., Leathwick, J.R., Young, R.G., 2012. Quantifying relationships between land-use gradients and structural and functional indicators of stream ecological integrity. Freshwater Biol. 57, 74-90.

Clarke, K., Warwick, R., 1998. A taxonomic distinctness index and its statistical properties. J. Appl. Ecol. 35, 523-531.

Cooper, S.D., Lake, P.S., Sabater, S., Melack, J.M., Sabo, J.L., 2013. The effects of land use changes on streams and rivers in mediterranean climates. Hydrobiologia 719, 383-425.

Crisp, D.T., Laffan, S., Linder, H.P., Monro, A., 2001. Endemism in the Australian flora. J. Biogeogr. 28, 183-198.

Daan, N., 2005. An afterthought: ecosystem metrics and pressure indicators. ICES J. Mar. Sci. J. Conseil. 62 (3), 612-613.

Dahm, V., Hering, D., Nemitz, D., Graf, W., Schmidt-Kloiber, A., Leitner, P., Melcher, A., Feld, C.K., 2013. Effects of physico-chemistry, land use and hydromorphology on three riverine organism groups: a comparative analysis with monitoring data from Germany and Austria. Hydrobiologia 704 (1), 389-415.

Development Core Team, R., 2017. R: A Language and Environment for Statistical Computing. R Foundation for Statistical Computing, Vienna, Austria. https://www. R-project.org/.

Dußling, U., Berg, R., Klinger, H., Wolter, C., 2004. Assessing the ecological status of river systems using fish assemblages. In: Steinberg, C., Calmano, W., Klapper, H., Wilken, R.D. (Eds.), Handbuch Angewandte Limnologie VIII. Ecomed Verlagsgruppe, Landsberg, pp. 1-84.

EFI + Consortium. 2009. Manual for the application of the new European Fish Index - EFI + , Improvement and spatial extension of the European Fish Index [online].

Elith, J., Leathwick, J.R., Hastie, T., 2008. A working guide to boosted regression trees. J. Animal Ecol. 77 (4), 802-813.

Elosegi, A., Gessner, M.O., Young, R.G., 2017. River doctors: learning from medicine to improve ecosystem management. Sci. Total Environ. 595, 294-302.

Emmrich, M., Brucet, S., Ritterbusch, D., Mehner, T., 2011. Size spectra of lake fish assemblages: responses along gradients of general environmental factors and intensity of lake-use. Freshw. Biol. 56 (11), 2316-2333.

Feld, C.K., de Bello, F., Dolédec, S., 2013. Biodiversity of traits and species both showweak responses to hydromorphological alteration in lowland river macroinvertebrates. Freshw. Biol. 59, 233-248.

Feld, C.K., Birk, S., Eme, D., Gerisch, M., Hering, D., Kernan, M., Maileht, K., Miscke, U., Ott, I., Pletterbauer, F., Poikane, S., Salgado, J., Sayer, C.D., van Wichelen, J., Malard, F., 2016. Disentangling the effects of land use and geo-climatic factors on diversity in European freshwater ecosystems. Ecol. Ind. 60, 71-83.

Ferreira, T., Oliveira, J., Caiola, N., de Sostoa, A., Casals, F., Cortes, R., Economou, A., Zogaris, S., García de Jalón, D., Ihe, M., Martínez-Capel, F., Pont, D., Rogers, C., Prenda, J., 2007. Ecological traits of fish assemblages from Mediterranean Europe and their responses to human disturbance. Fisheries Manag. Ecol. 14, 473-481.

Field, R., Hawkins, B.A., Cornell, H.V., Currie, D.J., Diniz-Filho, J.A.F., Guégan, J.-F., Kaufman, D.M., Kerr, J.T., Mittelbach, G.G., Oberdoff, T., O'Brien, E.M., Turner, J.R.G., 2009. Spatial species-richness gradients across scales: a meta-analysis. J. Biogeogr. 36, 132-147.

Froese, R., Pauly, D. (Eds.), 2016. FishBase. World Wide Web electronic publication version $(10 / 2016)$.

García de Jalón, D., González del Tánago, M., 1983. In: Estudio Boletín Estación Central de Ecología, pp. 57-69.

Hering, D., Johnson, R.K., Kramm, S., Schmutz, S., Szoszkiewicz, K., Verdonschot, P.F., 2006. Assessment of European streams with diatoms, macrophytes, macroinvertebrates and fish: a comparative metric-based analysis of organism response to stress. Freshw. Biol. 51 (9), 1757-1785.

Hering, D., Borja, A., Carstensen, J., Carvalho, L., Elliott, M., Feld, C.K., Heiskanen, A.S. Johnson, R.K., Moe, J., Pont, D., Solheim, A.L., 2010. The European Water Framework Directive at the age of 10: a critical review of the achievements with recommendations for the future. Sci. Total Environ. 408 (19), 4007-4019.

Herrera, S., Gutiérrez, J.M., Ancell, R., Pons, M.R., Frías, M.D., Fernández, J., 2012. Development and Analysis of a 50 year high-resolution daily gridded precipitation dataset over Spain (Spain02). Int. J. Climatol. 32, 74-85.

Hijmans R.J., Phillips, S., Leathwick, J., Elith, J., 2017. dismo: Species Distribution Modeling. R package version 1.1-4.

Izzo, C., Doubleday, Z.A., Grammer, G.L., Gilmore, K.L., Alleway, H.K., Barnes, T.C., Disspain, M.C., Giraldo, A.J., Mazloumi, N., Gillanders, B.M., 2016. Fish as proxies of ecological and environmental change. Rev. Fish. Biol. Fisher. 26 (3), 265-286.

Jeppesen, E., Moss, B., Bennion, H., Carvalho, L., DeMeester, L., Feuchtmayr, H., Friberg, N., Gessner, M.O., Hefting, M., Lauridsen, T.L., Liboriussen, L., 2010. Interaction of climate change and eutrophication. In: Climate Change Impacts on Freshwater Ecosystems, pp. 119-151.

Kail, J., Wolter, C., 2013. Pressures at larger spatial scales strongly influence the ecological status of heavily modified river water bodies in Germany. Sci. Total Environ. 454, 40-50.

Karr, J.R., 1981. Assessment of biotic integrity using fish communities. Fisheries 6 (6), 21-27.

Linder, H.P., 2001. Plant diversity and endemism in sub-Saharan tropical Africa. J. Biogeogr. 28, 169-182.

Logez, M., Pont, D., 2011. Development of metrics based on fish body size and species traits to assess European coldwater streams. Ecol. Ind. 11 (5), 1204-1215.

López-Bermúdez, F., García-Ruiz, J.M., 2008. La degradación del suelo por erosión hídrica en España. In: Erosión y degradación del suelo agrícola en España, pp. 11-51.

Maceda-Veiga, A., Mac Nally, R., de Sostoa, A., 2018. Environmental correlates of foodchain length, mean trophic level and trophic level variance in invaded riverine fish assemblages. Sci. Total Environ. 644, 420-429.

Marzin, A., Archaimbault, V., Belliard, J., Chauvin, C., Delmas, F., Pont, D., 2012 Ecological assessment of running waters: do macrophytes, macroinvertebrates, diatoms and fish show similar responses to human pressures? Ecol. Ind. 23, 56-65.

Marzin, A., Verdonschot, P.F., Pont, D., 2013. The relative influence of catchment, riparian corridor, and reach-scale anthropogenic pressures on fish and macroinvertebrate assemblages in French rivers. Hydrobiologia 704 (1), 375-388.

Mittelbach, G.G., Schemske, D.W., Cornell, H.V., Allen, A.P., Brown, J.M., Bush, M.B., Harrison, S.P., Hurlbert, A.H., Knowlton, N., Lessios, H.A., McCain, C.M., McCune, A.R., McDade, L.A., McPeek, M.A., Near, T.J., Price, T.D., Ricklefs, R.E., Roy, K., Sax, D.F., Schluter, D., Sobel, J.M., Turelli, M., 2007. Evolution and the latitudinal diversity gradient: speciation, extinc-tion and biogeography. Ecol. Lett. 10, 315-331.

Murphy, C.A., Casals, F., Solà, C., Caiola, N., de Sostoa, A., García-Berthou, E., 2013. Efficacy of population size structure as a bioassessment tool in freshwaters. Ecol. Ind. 34, 571-579.

Myers, N., Mittermeier, R.A., Mittermeier, C.G., da Fonseca, G.A.B., Kent, J., 2000. Biodiversity hotspots for conservation priorities. Nature 403, 853-858.

Oberdorff, T., Tedesco, P., Hugueny, B., Leprieur, F., Beauchard, O., Brosse, S., Dürr, H.H., 2011. Global and regional patterns in riverine fish species richness: a review. Int. J. Ecol. 2011, 1-12.

Odum, E.P., Finn, J.T., Franz, E.H., 1979. Perturbation theory and the subsidy-stress gradient. Bioscience 29, 349-352.

Pont, D., Hugueny, B., Rogers, C., 2007. Development of a fish-based index for the assessment of river health in Europe: the European fish index. Fish. Manage. Ecol. 14, 427-439.

Quintana, X., Brucet, S., Gascón, S., Badosa, A., López-Flores, R., Boix, D., Egozcue, J.J., 2008. A nonparametric method for the measurement of size diversity, with emphasis on data standardisation. Limnol. Oceanogr. Methods 6, 75-86.

Rivas-Martínez, S., Sánchez-Mata, D., Costa, M., 2004. Synoptical Worldwide Bioclimatic Classification System: Madrid. University Complutense of Madrid. http://www. globalbioclimatics.org/.

Schiemer, F., 2000. Fish as indicators for the assessment of the ecological integrity of large rivers. Hydrobiologia 422, 271-278.

Schmutz, S., Kaufmann, M., Vogel, B., Jungwirth, M., 2000. Methodische Grundlagen und Beispiele zur Bewertung der fischökologischen Funktionsfähigkeit österreichischer 
Fließgewässer. Project Report. Institute for Hydrobiology and Aquatic Ecosystem Management, University of Natural Resources and Applied Life Sciences, Vienna.

Segurado, P., Caiola, N., Pont, D., Oliveira, J.M., Delaigue, M., Ferreira, M.T., 2014.

Comparability of fish-based ecological quality assessments for geographically distinct Iberian regions. Sci. Total Environ. 476, 785-794.

Shannon, C.E., 1948. A mathematical theory of communication. Bell Syst. Tech. J. 27, 379-423.

Vannote, R.L., Minshall, G.W., Cummins, K.W., Sedell, J.R., Cushing, C.E., 1980. The river continuum concept. Can. J. Fish. Aquat. Sci. 37 (1), 130-137.

Vidal-Abarca, M.R., Santos-Martín, F., Martín-López, B., Sánchez-Montoya, M.M., Alonso, M.S., 2016. Exploring the capacity of water framework directive indices to assess ecosystem services in fluvial and riparian systems: towards a second implementation phase. Environ. Manage. 57 (6), 1139-1152.

Wagenhoff, A., Townsend, C.R., Phillips, N., Matthaei, C.D., 2011. Subsidy-stress and multiple-stressor effects along gradients of deposited fine sediment and dissolved nutrients in a regional set of streams and rivers. Freshw. Biol. 56, 1916-1936.

Wagenhoff, A., Townsend, C.R., Matthaei, C.D., 2012. Macroinvertebrate responses along broad stressor gradients of deposited fine sediment and dissolved nutrients: a stream mesocosm experiment. J. Appl. Ecol. 49, 892-902.

Wagenhoff, A., Liess, A., Pastor, A., Clapcott, J.E., Goodwin, E.O., Young, R.G., 2017.

Thresholds in ecosystem structural and functional responses to agricultural stressors can inform limit setting in streams. Freshw. Sci. 36 (1), 178-194.

Wolter, C., Lorenz, S., Scheunig, S., Lehmann, N., Schomaker, C., Nastase, A., García de Jalón, D., Marzin, A., Lorenz, A., Kraková, M., Brabec, K., 2013. Review on ecological response to hydromorphological degradation and restoration. Deliverable D1.3, a report of REFORM (REstoring Rivers FOR Effective Catchment MANAGEMENT), A

Collaborative Project (large-Scale Integrating Project) Funded by the European Commission within the 7th Framework Programme under Grant Agreement 282656. 